\title{
Impaired Priming of New Associations in Amnesia
}

\author{
Arthur P. Shimamura and Larry R. Squire \\ Veterans Administration Medical Center, San Diego, and Department of Psychiatry, University of California, San Diego
}

\begin{abstract}
We assessed priming of new associations in amnesic patients and healthy control subjects in a paradigm developed by Graf and Schacter (1985). Subjects were presented unrelated word pairs embedded in sentences (e.g., A BELL was hanging over the baby's CRADLE) and were asked to rate how well the sentences related the two words. Subjects were then given a word completion test. They were shown three-letter word stems and were asked to complete the stem with the first word that came to mind. In the same context condition, each word stem was presented together with the word that had appeared in the same sentence during study (e.g., BELL-CRA_--). In the different context condition, each stem was presented together with a new word that had ncver been presented (e.g., APPI.F-CRA . ). Control subjccts completed more words in the same context condition than in the different context condition. In contrast, amnesic patients did not complete any more words in the same context condition than in the different context condition. Indeed, across two experiments none of the amnesic patients exhibited consistent priming of new associations. Thus, although amnesic patients do exhibit entirely normal priming of preexisting memory representations. they do not appear to exhibit priming of new associations in this paradigm.
\end{abstract}

Neuropsychological studies of human amnesia have contributed to the understanding of normal memory functions (for reviews see Cermak, 1982; Hirst, 1982; RichardsonKlavehn \& Bjork, 1988; Schacter, 1987; Shimamura, in pressa; Squire, 1987; Wieskrantz, 1987). One important contribution is the demonstration that some memory functions can be dissociated from others. Thus, despite exhibiting severe impairment on conventional tests of memory such as recall, recognition, and paired-associate learning, amnesic patients are not impaired on all tests of memory. For example, skill learning, word priming effects, and adaptation-level effects can all be expressed by amnesic patients in a normal fashion (see Parkin, 1982; Schacter, 1987; Shimamura, 1986; Squire, 1987; Squire \& Zola-Morgan, 1988).

One aspect of memory that has been studied extensively in amnesic patients is the phenomenon of priming (for reviews, see Richardson-Klavehn \& Bjork, 1988; Schacter, 1987; Shimamura, 1986). Amnesic patients can exhibit normal repetition priming in a variety of paradigms, including word-stem completion (Diamond \& Rozin, 1984; Graf, Squire, \& Mandler, 1984; Squire, Shimamura, \& Graf, 1987; Warrington \& Weiskrantz, 1968, 1970), perceptual identification (Cermak, Talbot, Chandler, \& Wolbarst, 1985), lexical decision (Glass \& Butters, 1985; Moscovitch, 1982), spelling of homophones (Jacoby \& Witherspoon, 1982), and free association of related words (Gardner, Boller, Moreines, \& Butters, 1973; Graf,

This research was supported by the Medical Research Service of the Veterans Administration, by National Institute of Mental Health Grant MH24600, and by the Office of Naval Rescarch. We thank Joyce Zouzounis, Kim Rivero-Frink, and Loni Shutler for research assistance.

Arthur P. Shimamura is now at the Department of Psychology, University of California, Berkeley, California 94720. Correspondence concerning this article should be addressed to Larry R. Squire, Veterans Administration Medical Center (V116), 3350 La Jolla Village Drive. San Diego. California 92161.
Shimamura, \& Squire, 1985; Schacter, 1985; Shimamura \& Squire, 1984). Amnesic patients exhibit not only intact repetition priming but also intact semantic priming. For example, words can be primed by recently presented semantic associates or category cues, even when the cues themselves were not presented during study (Graf et al., 1985; Shimamura \& Squire, 1984). These findings have suggested a dissociation between a form of memory that is implicit, nondeclarative, or unconscious from a form of memory that is explicit, declarative, or conscious (see Baddeley, 1982; Graf \& Schacter, 1985; Jacoby \& Witherspoon, 1982; Squire \& Zola-Morgan, 1988).

A general feature of these demonstrations is that intact priming in amnesia occurs only for preexisting or unitized representations. Amnesic patients do not exhibit intact priming of nonwords (Cermak et al., 1985; Diamond \& Rozin, 1984) or unrelated word phrases (Schacter, 1985). As a result, many have suggested that priming in amnesia depends on a preserved ability to activate preexisting perceptual and/or semantic representations (Cermak et al., 1985; Graf et al., 1984; Rozin, 1976; Shimamura \& Squire, 1984).

Yet, there is also some evidence to suggest that amnesic patients can prime new associations in certain circumstances (Graf \& Schacter, 1985; Johnson, Kim, \& Risse, 1985; McAndrews, Glisky, \& Schacter, 1987; Moscovitch, Winocur, \& Mclachlan, 1986). In one study (Graf \& Schacter, 1985), subjects were presented a series of normatively unrelated word pairs (c.g., WINDOW-REASON), either embedded within a sentence or simply as word pairs. Subjects were encouraged to make elaborative associations between the words in each pair by asking them to rate how well a sentence related the two words or to generate their own sentence that included the two words. Word completion priming was then tested by showing subjects a three-letter word stem together with a word cue and asking them to complete the stem with the first word that came to mind. In the same context condition, test cues comprised the same word pairs that were presented for study (e.g., WINDOW-REA_-_). In the different context condition, 
word cues were different from the ones that were presented during study (e.g., OFFICER-REA_--). Priming of new associations was evaluated by determining if performance in the same context condition is better than performance in the different context condition.

Initial findings indicated that amnesic patients exhibited intact priming of new associations (Graf \& Schacter, 1985). However, further analyses showed that only "mildly amnesic" patients improved their word completion score in the presence of contextual cues. For severely amnesic patients, there was no context effect (Schacter \& Graf, 1986b). Recently, Cermak and colleagues showed that a group of patients with Korsakoff's syndrome did not exhibit priming of new associations in this paradigm (Cermak, Bleich, \& Blackford, 1988), though a patient with amnesia due to encephalitis (Patient S. S.) did demonstrate this priming effect (Cermak, Blackford, O'Connor, \& Bleich, 1988). If only less impaired patients exhibit priming of new associations, then it could be supposed that such priming effects depend on residual declarative or explicit memory. Alternatively, it is possible that the equivocal findings from amnesic patients are due not to differences in the severity of amnesia but to differences in its etiology or to differences in the extent of additional cognitive impairment. Different etiologies of amnesia can produce different patterns of cognitive impairment (see Moscovitch, 1982; Shimamura, in press-a; Squire, 1982). Thus, it remains possible that only certain etiologies of amnesia exhibit priming of new associations. It also remains possible that even severely amnesic patients might exhibit priming of new associations if their cognitive impairment were well circumscribed and restricted to memory dysfunction.

If priming of new associations were intact in amnesic patients, this finding would broaden the scope of preserved memory functions and create some difficulties for the hypothesis that preserved priming effects reflect an intact ability to activate preexisting representations. Yet, in view of the previous equivocal findings, it is not clear whether such priming effects generally occur in amnesic patients. We investigated priming of new associations in amnesic patients who are known to exhibit intact repetition and semantic priming effects (Graf et al., 1984; Graf et al., 1985; Shimamura \& Squire, 1984).

\section{Experiment 1}

\section{Method}

\section{Subjects}

Amnesic patients. We tested 12 amnesic patients: 6 with alcoholic Korsakoff's syndrome ( 4 men and 2 women) and 6 other patients with amnesia ( 4 men and 2 women). The 6 patients with Korsakof?s syndrome live in supervised facilities in San Diego County and have been studied as a group for several years (Shimamura \& Squire, 1984, 1988; Squire \& Shimamura, 1986). Of the 6 other amnesic patients, 3 of them became amnesic after an episode of anoxia or ischemia (A. B., G. D., and L. M.) and have been studied for several years (Shimamura \& Squire, 1988; Squire \& Shimamura, 1986). For L. M. magnetic resonance (MR) scans have identified bilateral medial tem- poral pathology. The 3 other patients were N. A., M. G., and W. H. Patient N. A. became amnesic for verbal material in 1960 when he sustained a stab wound to the brain with a miniature fencing foil (Squire, Amaral, Zola-Morgan, Kritchevsky, \& Press, in press; Teuber, Milner, \& Vaughan, 1968). Patient W. H. became amnesic in 1986, but without a known precipitating event. MR scans have identified bilateral medial temporal pathology. Patient M. G. became amnesic in 1986 following a bilateral thalamic infarction. Additional neuropsychological data for patients W. H. and M. G. can be found in Janowsky, Shimamura, Kritchevsky, and Squire (1989).

The present study was concerned with the overall performance of amnesic patients, and the patients will therefore be treated here as a single group (individual scores from the two experiments are presented in the Results section). The 12 amnesic patients averaged 54.1 years of age and 13.3 years of education. They had an average Wechsler Adult Intelligence Scale-Revised IQ (WAIS-R) score of 103.3. On the Wechsler Memory Scale-Revised (WMS-R), they scored 95.8 on Attention and Concentration, 74.0 on Verbal Memory, 76.1 on Visual Memory, 68.5 on General Memory, and 56.7 on Delayed Memory. The WAIS-R and WMS-R are standardized with a mean of 100 and a standard deviation of 15 . Thus, these patients scored within the normal range on the WAIS-R and on the Attention and Concentration index of the WMS-R. Yet, every patient scored at least 2 standard deviations below average on the Delayed Memory index.

Free recall of a short prose passage was 5.6 segments for immediate recall and 0 segments for delayed $(12 \mathrm{~min})$ recall ( 21 segments total). Average scores for copy and delayed recall $(12 \mathrm{~min})$ of a complex diagram (Rey-Osterreith figure) were 28.2 and 4.8 segments, respectively ( 36 segments total). Paired-associate memory of 10 unrelated noun-noun pairs on each of three successive trials was $0.7,0.7$, and 1.8. Also, on 5 successive study-test trials (Rey Auditory Verbal Learning Test) these patients averaged 4.3, 5.3, 5.6, 5.7, and 5.5 for immediate free recall of 15 nouns; and they averaged $21.8,24.5,25.1$, 26.1 , and 27.2 correct for yes-no recognition of 15 old nouns and 15 new nouns.

Neuropsychological screening and independent neurological examination indicated that memory impairment was the only remarkable deficit of higher cortical function. The amnesic patients averaged 133.2 points out of a possible 144 points on the Dementia Rating Scale (Coblentz et al., 1973), losing most of their points on the memory subportion of the test. All patients could draw a cube and a house in perspective, and none had aphasia or apraxia. Additional neuropsychological data for 10 of the 12 patients, as well as data for control subjects for the just-mentioned tests, can be found in Squire and Shimamura (1986).

Healthy control subjects. We tested 23 healthy control subjects (12 men and 11 women), who were employees or volunteers at the San Diego Veterans Administration Medical Center. They averaged 48.9 years of age and 13.9 years of education. We divided these healthy control subjects into two groups. The first group $(N=12)$ was given a test of word completion for new associations and tested in the same way as the amnesic patients. The second group $(N=11)$ provided a measure of word completion performance when no associated cue was provided during the word completion test (sec below for details).

\section{Materials}

We used a set of 40 sentences, which were kindly provided by Daniel Schacter, Each sentence included two critical words printed in capital letters (e.g., A BELL was hanging over the baby's CRADLE). The two critical words in each sentence were normatively unrelated. The first word was used as an associative cue in the word completion 
test, and the second word was used to assess word stem completion. The words were 4-10 letters long and had an average frequency count of 43.9 occurrences per million (Kučera \& Francis, 1967). All had different three-letter beginnings (stems), and each stem used to test word completion could be completed with at least 10 different common words. The sentences were printed individually on index cards. Two lists of 20 sentences each was constructed, one of which was presented for study.

In the word completion test, 10 of the 20 sentences that had been presented for study were tested in the same context condition. In this condition, each three-letter word stem was presented together with the word that had appeared in the same sentence during study (e.g., BELL_CRA_...). The other 10 sentences that had been presented for study were tested in the different context condition. In this condition, each stem was presented together with a new word that had never been presented (e.g. APPL.E-CRA__-). These 10 "different" cue words were obtained from cue words in the unpresented list. The 10 cue words used in the same context condition for one subject were used in the different context condition for another subject. We also included a baseline condition in which word completion was assessed for 10 cue-word/word stem pairs that had never been presented (c.g. STORM-FIL_-_). These 10 baseline pairs were obtained from the remaining 10 unused word pairs in the unpresented list. We constructed test forms so that the cue word/word stem pairs used in the various conditions were matched in terms of the level of baseline completion. In addition, across subjects, we counterbalanced test items in such a way that a given word pair was used equally often in the three word completion conditions (same, different, baseline).

\section{Procedure}

We used the procedure originally developed by Graf and Schacter (1985; Schacter \& Graf, 1986a). Subjects were presented 20 sentences and asked to read each one aloud. They were also asked to rate the degree to which each sentence related the two critical words in a meaningful way (sce Graf \& Schacter, 1985). Subjects rated each sentence on a 5 -point scale $(1=$ does not relate the words at all, $5=$ relates the words quite meaningfilly). To encourage subjects to read the sentences carefully, we included six filler sentences that did not relate words meaningfully (e.g., The humid PAINTER ventilated the LEASE). The filler sentences were intermixed with the other sentences. A practice sentence was also used at the beginning of the study phase in order to familiarize the subjects with the procedure. A card showing the 5-point rating scale was always displayed in front of the subjects. The presentation rate was self-paced. Following presentation of the list of 20 sentences, the same sentences were presented again in the same way but in a different random order. As in the experiments by Graf and Schacter, subjects were given intentional learning instructions-they were asked "to try to remember each sentence."

Between the study phase and the word completion test, we gave a filler task. Subjects were provided a form on which each letter of the alphabet was printed in alphabetical order. Subjects were then given $3 \mathrm{~min}$ to try to generate the name of a city beginning with each letter. They werc instructed to report the first city that came to mind. This "city-generation" task was used by Schacter and Graf (1986a) as a way to encourage implicit memory strategies during the word completion test.

For the word completion test, subjects were asked to read each cue word aloud and then to write down the first word that came to mind that could be used to complete the three-letter stem. Subjects were told: "The word you read aloud will sometimes help you think of a word that can be used to complete the three-letter word beginning." Any regular English word was accepted, but no proper names were accepted. Subjects were asked to try to respond as quickly as possible.
A practice test trial was presented to makc sure subjects understood the instructions. We scored plural or singular versions of target words as correct responses, but no other grammatical variations were scored as correct.

Following the word completion test, we gave an explicit, pairedassociate memory test for the two critical words in each sentence. The cue word was presented for each of the 20 sentences that had been studied (e.g., BELL), and subjects were asked to recall the other word that had appeared in capital letters in the same sentence (e.g., CRADLE).

A second group of 11 healthy control subjects was tested in the identical way except that in the word completion test no cue words appeared together with the three-letter stems (no-cues condition). That is, 20 word stems in the word completion test could be completed to form words that had been presented during the study phase, and an additional 10 word stems were included to assess baseline completion performance. Previous studies of word completion using similar test conditions showed that amnesic patients and control subjects exhibit comparable levels of priming. Data from this control group provided a way to evaluate word completion performance in those conditions where a cue word accompanied the word stem. Compared with word completion performance in this no-cues condition, performance might be facilitated in the same context condition, inhibited in the different context condition, or both facilitated in one condition and inhibited in the other.

In summary, amnesic patients and healthy control subjects were presented 20 sentences with two words capitalized in each sentence. They were asked to rate how meaningfully each sentence related the two words. Following a 3 -min filler task (the city-generation task), subjects took a word completion test consisting of 30 unique cueword/word stem pairs in a mixed order (10 in the same context condition, 10 in the different context condition, and 10 in the baseline condition). We then assessed paired-associate memory for the word pairs in each sentence. Finally, we tested a second control group in the identical manner, except that no cue words were provided in the word completion test.

\section{Results and Discussion}

To evaluate word completion performance, we calculated a completion score for each subject by subtracting the completion score obtained in the baseline condition from the completion score obtained in the same context and different context conditions. In all conditions, word completion performance was greater than baseline performance $(t \mathrm{~s}>2.42$, $p s<.05$ ). For healthy control subjects, word completion performance in the same context condition was significantly greater than performance in the different context condition, $t(11)=2.22, p<.05$; see Figure 1 . In contrast, amnesic patients exhibited the same level of word completion performance in the two context conditions, $t(11)=0.15, p>.4)$. A 2 $\times 2$ analysis of variance (ANOVA) was performed on these data, but as a result of subject variability the Group $\times$ Context Condition interaction was not significant, $F(1,22)=1.75, p$ $=.19, M S_{\mathrm{c}}=2.01$. In fact, the effect of context exhibited by healthy control subjects, in both this experiment and in those of Graf and Schacter (1985; Schacter \& Graf, 1986a), was quite small and amounted to about one more word completed in the same condition than in the different context condition.

Figure 1 also shows performance by healthy control subjects in the no-cues condition. Numerically, the word completion score obtained in the no-cues condition $(11 \%)$ was in between 
that obtained by healthy subjects in the same $(21 \%)$ and different $(9 \%)$ context conditions. The score in the no-cues condition was marginally different from that observed in the same context condition, $t(21)=1.96, p=.06$, but not significantly different from that observed in the different context condition, $t(21)=-.056, p>.1)$. These findings suggest that for healthy control subjects the same context condition facilitated word completion performance. For amnesic patients, the word completion score in both the same and different condition was numerically larger than that obtained by healthy control subjects in the no-cues condition, but these differences did not approach statistical significance $(t s<1.4 ; p s>.1)$. Thus, for amnesic patients, word completion performance was not measurably facilitated by the presence of same-context cue words.

Performance on the city-generation task was comparable for healthy control subjects (18.4 cities generated) and amnesic patients ( 16.5 cities generated), $t(22)=1.14, p>.2$. As expected, amnesic patients were severely impaired on the paired-associate memory test, $t(22)=11.3, p<.01$. Except for one anoxic-ischemic patient, who could recall one word, none of the patients could recall a single word from the study list. Healthy control subjects correctly recalled an average of 12.8 words out of 20 .

\section{Experiment 2}

A replication study of the first experiment was conducted in order to confirm that amnesic patients exhibit impaired priming of new associations. Four of the 12 amnesic patients did perform numerically better in the same context condition than in the different context condition (Table 1), and it seemed possible that some amnesic patients might perform this way consistently. Accordingly, the 12 amnesic patients were tested as in Experiment 1 but with a different list of sentences.

\section{Method}

\section{Subjects}

Amnesic patients. See Experiment 1.

Ilealthy control subjects. We tested 26 healthy control subjects (13 men and 13 women), who were employees or volunteers at the

Table 1

Word Completion Performance by Amnesic Patients

\begin{tabular}{|c|c|c|c|c|}
\hline \multirow[b]{2}{*}{ Patient } & \multicolumn{2}{|c|}{ Experiment 1} & \multicolumn{2}{|c|}{ Experiment 2} \\
\hline & Same & Different & Same & Different \\
\hline KI & 4.0 & 3.0 & 3.0 & 4.0 \\
\hline $\mathrm{K} 2$ & 2.0 & 2.0 & 1.0 & 2.0 \\
\hline K3 & 1.0 & 1.0 & 2.0 & 3.0 \\
\hline K4 & 2.0 & 4.0 & 4.0 & 3.0 \\
\hline K5 & 3.0 & 4.0 & 0.0 & 2.0 \\
\hline K6 & 3.0 & 5.0 & 2.0 & 2.0 \\
\hline $\mathrm{AB}$ & 1.0 & 4.0 & 2.0 & 1.0 \\
\hline GD & 3.0 & 3.0 & 5.0 & 2.0 \\
\hline $\mathrm{MG}$ & 0.0 & 0.0 & 1.0 & 2.0 \\
\hline WH & 4.0 & 1.0 & 2.0 & 2.0 \\
\hline LM & 5.0 & 2.0 & 2.0 & 2.0 \\
\hline NA & 4.0 & 2.0 & 2.0 & 2.0 \\
\hline
\end{tabular}

San Diego Veterans Administration Medical Center. They averaged 54.0 years of age and 13.9 years of education. We assigned these healthy control subjects to two groups. The first group $(N=16)$ was given a test of word completion for new associations in the same way that the amnesic patients were tested. The second group $(N=10)$ provided a measure of word completion performance in the no-cues condition.

\section{Materials and Procedure}

A new set of 40 sentences was constructed according to the same criteria used for the previous set. The words were 4-10 letters long and had an average frequency count of 42.4 occurrences per million (Kučera \& Francis, 1967). All had different three-letter stems, and each stem used to test word completion could be completed to form at least 10 different common words. The procedure was identical to the one used in Experiment 1.

\section{Results and Discussion}

In this replication study, the pattern of word completion performance was similar to that observed in the first experiment. However, overall word completion levels were somewhat lower (see Figure 1). Word completion performance was above baseline levels in all conditions $(t \mathrm{~s}>2.97, p \mathrm{~s}<.05)$, except for the different context condition for healthy control subjects, $t(9)=0.78, p>.2$ ). As in Experiment 1, healthy control subjects completed more words in the same context condition than in the different context condition, $t(15)=$ $2.32, p<.05$. In contrast, amnesic patients exhibited virtually the same level of completion performance in the two context conditions. As in Experiment 1, a $2 \times 2$ A.Nova did not reveal a Group $\times$ Context Condition interaction, though in this case the interaction approached significance, $F(1,26)=3.21, p<$ $.08, M S_{\mathrm{c}}=1.11$.

Performance of healthy control subjects in the no-cues condition was not significantly different from the performance of healthy control subjects or amnesic patients in either of the two context conditions ( $t \mathrm{~s}<1.4, p \mathrm{~s}>.1$ ). As in Experiment 1, the word completion score of healthy control subjects in the no-cues $(9.5 \%)$ condition was numerically between that observed in the same (13\%) and different $(4 \%)$ conditions. These findings suggest that in control subjects both facilitation and inhibition effects were occurring in the same and different conditions, respectively. For amnesic patients, the word completion score obtained in the same and different context conditions was similar to that exhibited by healthy control subjects in the no-cues condition. Consequently, for amnesic patients word completion performance was not affected by the associated word cues.

Performance on the city-gencration task was again comparable for healthy control subjects ( 19.7 cities generated) and amnesic patients ( 18.0 cities generated), $t(26)=1.13, p>.2$. Also, amnesic patients were severely impaired on the pairedassociate memory test. Except for the same anoxic-ischemic paticnt who again recalled one word pair, none of the patients could recall any words. Healthy control subjects averaged 10.6 words correct out of 20 .

In summary, the findings reported here for middle-aged healthy control subjects replicate the findings of Graf and Schacter $(1985,1987)$, which were based on college students. 


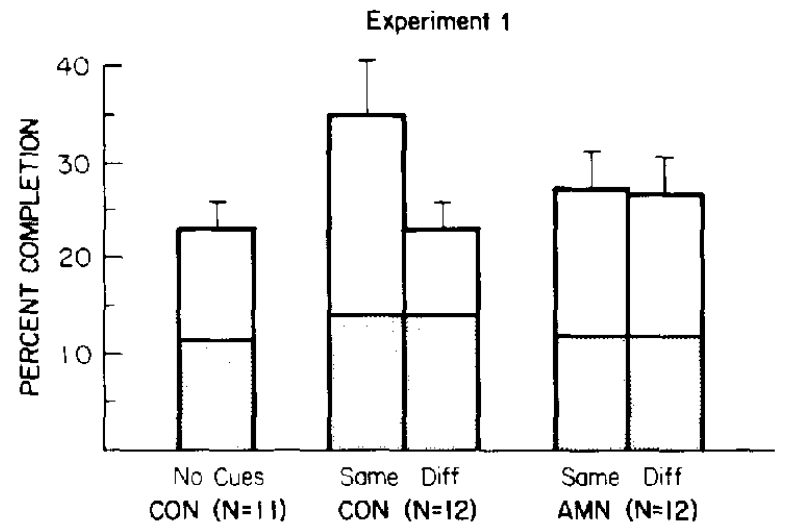

Experiment 2

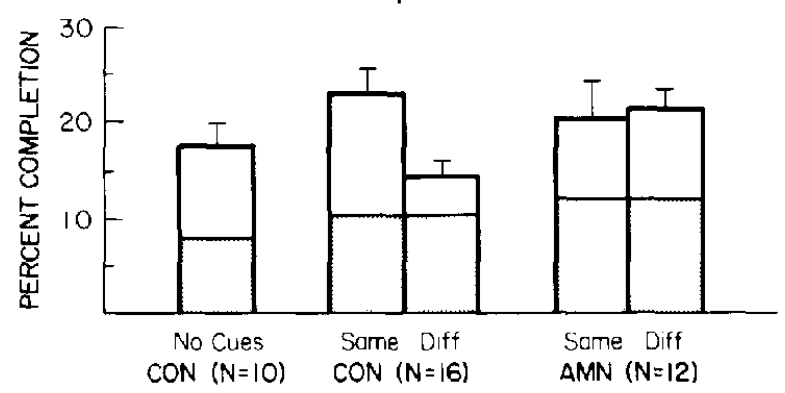

Figure 1. Top panel: Word completion performance in Experiment 1 (shaded area indicates hascline completion performance). ( $\mathrm{CON}=$ healthy control subjects in the no-cues condition and in the same and different context conditions; $\mathrm{AMN}=$ amnesic patients in the same and different context conditions.) Bottom panel: Word completion performance in the replication study (Experiment 2 ) for the same conditions.

Word completion performance was better in the same context condition than in the different context condition. Yet, word completion performance by amnesic patients was not affected by the context condition. Across two experiments, amnesic patients completed on average only 0.1 more items $(1 \%)$ in the same context condition than in the different context condition. In contrast, healthy control subjects completed 1.1 more items $(11 \%)$ in the same context condition than in the different context condition. Tablc 1 displays the individual scores for amnesic patients in both experiments. As can be seen from the individual scores, some amnesic patients did exhibit on one test a score that was two or three items greater in the same context condition than in the different context condition. Yet, none of the amnesic patients showed a consistent context effect across both experiments. Because we initially constructed test sets so that baseline completion levels were comparable across test sets, the failure to observe consistent priming of new associations across tests could not be attributed to large test item effects. Instead, the data for individual subjects strengthen the point that amnesic patients exhibit impaired priming performance in this paradigm.

\section{General Discussion}

Word completion performance by amnesic patients was not significantly facilitated by presenting cue words that were newly associated to the target words. Thus, the present findings fail to confirm initial evidence of intact priming of new associations in amnesia (Graf \& Schacter, 1985), but they are consistent with subsequent reports that severely amnesic patients do not exhibit this priming effect (Cermak, Bleich, \& Blackford, 1988; Schacter \& Graf, 1986b). In the present study, none of the 12 amnesic patients exhibited consistent priming of new associations across two testings. Yet, these same patients have previously exhibited intact semantic and repetition priming effects in a number of studies (Graf et al., 1984; Graf et al., 1985; Shimamura \& Squire, 1984).

It should be noted that the overall level of word completion performance by amnesic patients in the present study (24\%, averaged across both experiments) was lower than in previous studies of word completion (30\%-50\%, Graf et al., 1984; Shimamura et al., 1987; Squire et al., 1987). There were several methodological differences between this and previous studies. First, rather than presenting a single word in isolation, two target words were presented in the context of a sentence. Second, rather than asking subjects to study words by making judgments about single words (e.g., liking judgments), subjects were asked to form associations between two words. Third, rather than giving the word completion test immediately after the study phase, it was delayed by about $3 \mathrm{~min}$, during which the city-generation task was given.

Previous findings suggested that priming of new associations is exhibited by patients termed "mildly" amnesic, but not by those termed "severely" amnesic (Schacter \& Graf, 1986b). Terms like mild, moderate, and severe are rather imprecise descriptions of memory impairment and are likely to be used differently by different researchers. The term amnesia typically refers to a severe and selective disorder of long-term memory, certainly to a disorder that is clinically significant (see Squire \& Shimamura, 1986). The present findings for 12 amnesic patients who themselves vary in severity, and other findings for 8 patients with Korsakoff's syndrome (Cermak, Bleich, \& Blackford, 1988), suggest that amnesic study patients do not in general exhibit priming of new associations in this paradigm. Perhaps the "mildly" impaired patients tested by Schacter and Graf (1986b) are best described as memory impaired but not amnesic. In any case, it would appear that memory impairment must be quite mild if priming of new associations is to be observed.

On the basis of this and previous studies, one can ask whether priming of new associations is found in some kinds of amnesia but not in others. In the present study, we tested 6 patients with Korsakoff's syndrome, 4 patients with presumed or demonstrated medial temporal pathology, and 2 patients with diencephalic lesions (M. G. and N. A.). Averaged across the two experiments, the context effect (i.e., completion performance in the same condition minus completion performance in the different condition) was $-6.7 \%$ for patients with Korsakoff's syndrome, $8.7 \%$ for patients with presumed or demonstrated medial temporal damage, $2.5 \%$ for patients with diencephalic lesions, and $10.5 \%$ for age-matched control subjects. These findings from patients with Korsakoff's syndrome agree with other recent findings (Cermak, Bleich, \& Blackford, 1988) in which patients with Korsakoff's syndrome failed to exhibit a context effect $(0 \%)$. In that study, however, age-matched control subjects also failed to exhibit any context 
effect $(-8 \%)$. With respect to the 4 patients with presumed or demonstrated medial temporal pathology from the present study, their context effect approached the score for control subjects, but it should be noted that none of these 4 patients exhibited consistent context effects across the two experiments. Moreover, another anoxic patient tested by Schacter and Graf (1986b) failed to exhibit any context effect $(0 \%$; the context effect for age-matched control subjects was $11.0 \%$ ).

Two patients with amnesia due to encephalitis have also been tested. Schacter and Graf (1986b) tested an encephalitic patient who did not exhibit a context effect $(-4 \%)$; but Cermak, Blackford et al. (1988) tested an encephalitic patient (Case S.S.) who exhibited a context effect of $35 \%$. Finally, Schacter and Graf (1986b) tested 5 head-injured patients ( 3 were mildly amnesic and 2 were severely amnesic), who exhibited an average context effect of $12 \%$. The context effect, however, was variable, ranging from $-8 \%$ to $21 \%$. Consequently, it appears that the etiology of amnesia does not determine which patients will exhibit intact priming of new associations.

It appears that the degree of residual declarative memory, rather than etiology, more strongly determines the level of "priming" of new associations. Amnesic patients can exhibit significant residual memory on explicit tests of cued recall and recognition memory (e.g., Shimamura \& Squire, 1988). In the present study, the magnitude of the context effect for individual amnesic patients ranged from -1.5 items to +1.5 items (averaged across two experiments). To test whether the effect of context on word completion was related to residual declarative memory, we correlated each patient's context effect score with his or her score from the General Memory index of the WMS-R (which includes measures of recall and paired-associate learning). We found a significant positive correlation between the context effect and the General Memory index (Spearman rank order correlation $=.56, p<.05$ ). In contrast, the overall level of word completion priming (the average performance across both same and different context conditions) was not significantly correlated with the General Memory index (Spearman correlation $=.17$ ). This finding is consistent with the view that priming of new associations depends significantly on declarative memory, whereas the repetition priming effect itself does not.

Other findings with normal subjects are consistent with the view that declarative memory contributes to priming of new associations. For example, priming of new associations in normal subjects occurs only if the study task ensures elaborative encoding of the new associations (Schacter \& Graf, 1986a). In contrast, repetition priming is not affected or only slightly affected by the degree of elaborative encoding (Graf, Mandler, \& Haden, 1982; Graf et al., 1984). At the same time, at least some of the processes involved in priming of new associations seem to be different from those involved in conventional, explicit memory tests. For example, priming of new associations was less sensitive to prior-list interference effects than cued recall (Graf \& Schacter, 1987). Moreover, priming of new associations was affected more by acrossmodality shifts (i.e., visual vs. auditory presentations) than explicit memory (Schacter \& Graf, 1989). Thus, the findings from normal subjects suggest that priming of new associations depends in some respects on declarative memory but that this priming effect can also be dissociated from conventional measures of declarative memory. How can these conclusions be reconciled with the findings for amnesic patients, which suggest a dissociation between declarative memory and repetition priming but an association between declarative memory and priming of new associations?

One possibility is that the memory system damaged in amnesia is necessary to form new associations, but once they are formed, priming proceeds automatically and implicitly at the time of retrieval (Shimamura, 1986). By this view, amnesic patients are impaired because they cannot adequately establish new associations. Dissociations are observed in studies of normal subjects because, once the association is formed, the processes are distinct from declarative memory. Patients prescribed ECT could provide one way to test this view because these patients could be asked to form new associations prior to treatment-that is, prior to the onset of amnesia-and then asked to retrieve the information implicitly while they are amnesic. Unfortunately, this paradigm is not well suited for such a test because the context effect is quite small, even at short retention intervals.

Amnesic patients have been reported to exhibit priming of new associations in other paradigms. Johnson et al. (1985) demonstrated normal preference biases for recently presented melodies in patients with Korsakoff's syndrome. The melodies were Korean songs so that it was unlikely that the preference biases were based completely on preexisting representations. However, Johnson et al. (1985) did not find normal preference biases for a novel face depicted as a "good guy" over a face depicted as a "bad guy." Perhaps the normal priming effect obtained with repeated melodies was based on the unitization of preexisting melodic sequences rather than on the formation of completely new representations. One way to test this hypothesis would be to determine if amnesic patients exhibit a normal preference bias for repeated random sequences of tones.

In another study (McAndrews et al., 1987), amnesic patients were given ambiguous sentences (e.g., "The haystack was important because the cloth ripped"; see Aubel \& Franks, 1979). Each sentence could be understood easily when a critical word was presented (e.g., parachute). Amnesic patients were presented sentences and the associated critical words, and then after a 1-week retention interval they were asked to explain the sentences without the critical word. Amnesic patients exhibited good retention of the meaning of the sentences. Yet, performance was not normal. Moreover, in another study, the encephalitic Patient S. S. exhibited severely impaired performance in this paradigm (Cermak, Blackford et al., 1988).

Finally, Moscovitch et al. (1986) asked memory-impaired patients ( 3 patients had early-stage Alzheimer's disease, 1 had an episode of anoxia, 1 had an aneurysm, 1 had a head injury, and 2 had unknown etiologies) to read sentences or unrelated word pairs. Following initial reading of this material, the time required to read the same material again was compared with the time required to read different or recombined sentences or word pairs. Memory-impaired patients exhibited faster reading times for previously presented sentences or word pairs, compared with the reading times for new or recombined stimuli. The degree of facilitation for previously presented 
sentences or word pairs was comparable to that of control subjects. Yet, in order to control for differences in baseline reading speed between patients and control subjects, Moscovitch et al. (1986) slowed the reading speed of control subjects by presenting stimuli in a visually degraded manner. As a result, it is somewhat difficult to determine if priming was entirely intact in the memory-impaired patients. Also, findings of preserved priming of new associations in patients with dementia due to early-stage Alzheimer's disease is difficult to interpret because such patients exhibit impaired repetition and semantic priming (Salmon, Shimamura, Butters, \& Smith, 1988; Shimamura, Salmon, Squire, \& Butters, 1987).

At present, the findings from amnesic patients indicate that performance on tests of priming of new associations is impaired and is related to the severity of amnesia. In contrast, studies of repetition and semantic priming indicate that priming of preexisting representations is entirely preserved in amnesia and thus can be completely dissociated from the kind of memory that is impaired. Although tests of priming of new associations have yielded "good" (but subnormal) performance by some amnesic patients, such findings are not sufficient evidence for a dissociable memory process because the findings could depend on residual explicit memory abilities. Under some circumstances, spurious dissociations could arise as a result of test sensitivity artifacts such as ceiling or floor effects (see Shimamura, in press-b). For example, amnesic patients may perform nearly as well as normal subjects on an extremely easy explicit memory test yet fail to make any responses on a free recall test. To determine whether any particular example of good performance reflects a spared capacity, one needs to know how control subjects would perform on the same test if they were assessed at a time when their performance on standard explicit memory tests were weakened to the level of amnesic patients. If control subjects with weakened memory also exhibited good performance on the test of interest, then the pattern of performance observed in amnesic patients is probably a reflection of weak memory, rather than an indication of a spared memory capacity. This kind of research strategy would benefit future priming studies with amnesic patients whenever performance is poorer than normal but better than what was expected on tests of explicit memory.

In the present study, word completion priming for amnesic patients was not significantly facilitated by the presence of word cues that had been newly associated with target words. Moreover, across individual patients the context priming effect was inversely correlated with the severity of amnesia. Thus, the ability to show priming of new associations appears to depend on residual declarative memory abilities. Importantly, these same patients do exhibit entirely normal semantic and repetition priming effects. The findings are consistent with the view that priming effects in amnesia depend on an intact ability to activate preexisting representations, whereas priming of new associations depends significantly on memory processes impaired in amnesia.

\section{References}

Aubel, P. M., \& Franks, J. J. (1979). Effort toward comprehension: Elaboration or "aha"? Memory \& Cognition, 7, 426-434.
Baddeley, A. D. (1982). Domains of recollection. Psychological Review, 89, 708-729.

Cermak, L. S. (Ed.) (1982). Human memory and amnesia. Hillsdale, NJ: Erlbaum.

Cermak, L. S., Blackford, S. P., O'Connor, M., \& Bleich, R. P. (1988). The implicit memory ability of a patient with amnesia due to encephalitis. Brain and Cognition, 7, 145-156.

Cermak, L. S., Bleich, R. P., \& Blackford, S. P. (1988). Deficits in the implicit retention of new associations by alcoholic Korsakoff patients. Brain and Cognition, 7, 312-323.

Cermak, L. S., Talbot, N., Chandler, K., \& Wolbarst, L. R. (1985). The perceptual priming phenomenon in amnesia. Neuropsychologia, 23, 615-622.

Coblentz., J. M., Mattis, S., Zingesser, L. H., Kasoff, S. S., Wisniewski, H. M., \& Katzman, R. (1973). Presenile dementia: Clinical aspects and evaluation of cerebrospinal fluid dynamics. Archives of Neurology, 29, 299-308.

Diamond, R., \& Rozin, P. (1984). Activation of existing memories in anterograde amnesia. Journal of Abnormal Psychology, 93, 98105.

Gardner, H., Boller, F., Moreines, J., \& Butters, N. (1973). Retrieving information from Korsakoff patients: Effects of categorical cues and reference to the task. Cortex, 9, 165-175.

Glass, A. L., \& Butters, N. (1985). The effects of associations and expectations on lexical decision making in normals, alcoholics, and alcoholic Korsakoff patients. Brain and Cognition, 4, 465 476.

Graf, P., Mandler, G., \& Haden, P. E. (1982). Simulating amnesic symptoms in normals. Science, 218, 1243-1244.

Graf, P., \& Schacter, D. L. (1985). Implicit and explicit memory for new associations in normal and amnesic subjects. Journal of Experimental Psychology: Learning. Memory, and Cognition, 11, $501-518$

Graf, P., \& Schacter, D. L. (1987). Selective effects of interference on implicit and explicit memory for new associations. Journal of Experimental Psychology: Learning, Memory, and Cognition, 13, 45-53.

Graf, P., Shimamura, A. P., \& Squire, L. R. (1985). Priming across modalitizs and priming across category levels: Extending the domain of preserved function in amnesia. Journal of Experimental Psychology: Learning. Memory and Cognition, 11, 386-396.

Graf, P., Squire, L. R., \& Mandler, G. (1984). The information that amnesic patients do not forget. Journal of Experimental Psychotogy: Learning, Memory, and Cognition, 10, 164-178.

Hirst, W. (1982). The amnesic syndrome: Descriptions and explanations. Psychological Bulletin, 91, 435-460.

Jacoby, L. L., \& Witherspoon, D. (1982). Remembering without awareness. Canadian Journal of Psychology, 32, 300-324.

Janowsky, J. S., Shimamura, A. P., Kritchevsky, M., \& Squire, L. R. (1989). Cognitive impairment following frontal lobe damage and its relevance to human amnesia. Bchavioral Neuroscience, 103, $548-560$.

Johnson, M. K., Kim, J. K., \& Risse, G. (1985). Do alcoholic Korsakoff's syndrome patients acquire affective reactions? Journal of Experimental Psychology: Learning, Memory, and Cognition, 11, 22-36.

Kucera, M., \& Francis, W. (1967). Computational analysis of presentday American English. Providence, RI: Brown University Press.

Mattis, S. (1976). Dementia rating scale. In R. Bellack \& B. Karasu (Eds.), Geriatric psychiatry (pp. 77-121). New York: Grune \& Stratton.

McAndrews, M. P., Glisky, E. L., \& Schacter, D. L. (1987). When priming persists: Long-lasting implicit memory for a single episode in amnesic patients. Neuropsychologia, 25, 497-506.

Moscovitch, M. (1982). Multiple dissociations of function in amnesia. In L. Cermak (Ed.), Human memory and amnesia (pp. 337-370). Hillsdale, NJ: Erlbaum. 
Moscovitch, M., Winocur, G., \& McLachlan, D. (1986). Memory as assessed by recognition and reading time in normal and memoryimpaired people with Alzheimer's disease and other neurological disorders. Journal of Experimental Psychology: General, 115, 331347.

Parkin, A. J. (1982). Residual learning capability in organic amnesia. Cortex, 18, 417-440.

Richardson-Klavehn, A., \& Bjork, R. A. (1988). Measures of memory. Annual Review of Psychology, 39, 475-543.

Rozin, P. (1976). The psychobiological approach to human memory. In M. R. Rosenzweig \& E. L. Bennett (Eds.), Neural mechanisms of learning and memory (pp. 3-46). Cambridge, MA: MIT Press.

Salmon, D. P., Shimamura, A. P., Butters, N., \& Smith, S. (1988). Lexical and semantic priming deficits in patients with Alzheimer's disease. Journal of Clinical and Experimental Neuropsychology, 4, 477-494.

Schacter, D. L. (1985). Priming of old and new knowledge in amnesic patients and normal subjects. Annals of the New York Academy of Sciences, 444, 41-53.

Schacter, D. L. (1987). Implicit memory: History and current status. Journal of Experimental Psychology: Learning. Memory and Cognition, 13, 50I-518.

Schacter, D. L., \& Graf, P. (1986a). Effects of elaborative processing on implicit and explicit memory for new associations. Journal of Experimental Psychology: Learning. Memory, and Cognition, I2, 432-444.

Schacter, D. L., \& Graf, P. (1986b). Preserved learning in amnesic patients: Perspectives from research on direct priming. Journal of Clinical and Experimental Neuropsychology, 6, 727-743.

Schacter, D. L., \& Graf, P. (1989). Modality specificity of implicit memory for new associations. Journal of Experimental Psychology: Learning, Memory, and Cognition, 15, 3-12.

Shimamura, A. P. (1986). Priming effects in amnesia: Evidence for a dissociable memory function. Quarterly Journal of Experimental Psychology, 38A, 619-644.

Shimamura, A. P. (in press-a). Disorders of memory: The cognitive science perspective. In F. Boller \& J. Grafman (Eds.), Handbook of neuropsychology. Amsterdam, The Netherlands: Elsevier.

Shimamura, A. P. (in press-b). Forms of memory: Issues and directions. In J. I. McGaugh, N. M. Weinberger, \& G. Lynch (Eds.), Brain organization and memory: cells, systems, and circuits. New York: Oxford University Press.
Shimamura, A. P., Salmon, D. P., Squire, L. R., \& Butters, N. (1987). Memory dysfunction and word priming in dementia and amnesia. Behavioral Neuroscience, 101, 347-351.

Shimamura, A. P., \& Squire, L. R. (1984). Paired-associate learning and priming effects in amnesia: A neuropsychological study. Journal of Experimental Psychology: General, 113, 556-570.

Shimamura, A. P., \& Squire, L. R. (1988). Long-term memory in amnesia: Cued recall, recognition memory, and confidence ratings. Journal of Experimental Psychology: Learning, Memory, and Cognition, 14, 763-770.

Squire, L. R. (1982). Comparisons between forms of amnesia: Some deficits are unique to Korsakof's syndrome. Journal of Experimental Psychology: Learning, Memory, and Cognition, 8, 560-571.

Squire, I. R. (1987). Memory and brain. New York: Oxford University Press.

Squire, L. R., Amaral, D. G., Zola-Morgan, S., Kritchevsky, \& Press, $\mathrm{G}$. (in press). Description of brain injury in the amnesic patient $\mathrm{N}$. A. based on magnetic resonance imaging. Experimental Neurology.

Squire, L. R., \& Shimamura, A. P. (1986). Characterizing amnesic patients for neurobehavioral study. Behavioral Neuroscience, 100 , 866-877.

Squire, L. R., Shimamura, A. P., \& Graf, P. (1987). Strength and duration of priming effects in normal subjects and amnesic patients. Neuropsychologia, 25, 195-210.

Squire, L. R., \& Zola-Morgan, S. (1988). Memory: Brain systems and behavior. Trends in Neuroscience, 22, 170-175.

Teuber, H. L., Milner, B., \& Vaughan, H. G. (1968). Persistent anterograde amnesia after stab wound of the basal brain. Neuropsychologia, 6, 267-282.

Warrington, E. K., \& Weiskrantz, L. (1968). New method of testing long-term retention with special reference to amnesic patients. Nature, 217, 972-974.

Warrington, E. K., \& Weiskrantz, L. (1970). The amnesic syndrome: Consolidation or retrieval? Nature, 228, 628-630.

Weiskrantz, L. (1987). Neuroanatomy of memory and amnesia: A case for multiple memory systems. IIuman Neurobiology, 6, 93105 .

Received March 14, 1988

Revision received September 22, 1988

Accepted October 10, 1988 